CSs and serves as a yoked control for the other CS. The other S has a punishment contingency on one $\mathrm{CS}$ and serves as a yoked control for the other CS. The complete package of these four experimental cases permits Church's bias to be studied in all of its possible permutations, since careful analysis shows that it may contribute to an observed effect via a single cell of the four-fold table in the first two cases mentioned above, via two cells additively in one of the latter two cases (the last), and via none of the four cells in one of the cases (the third). Additional applications in other research areas may prove even more fruitful. REFERENCES

CHURCH, R. M. Systematic effect of random error in the yoked control design. Psychol Bull, 1964, 62, 122-131.

COCHRAN, W. G. \& COX, GERTRUDE, M. Expenimental designs New York: Wiley, 1957.

GRANT, D. A. The statistical analysis of a frequent experimental design. Amer. J. Psychol, 1949, 62, 119-122.

GRICE, G. R., \& HUNTER, J. J. Stimulus intensity effects depend upon the type of experimental design. Psychol Rev., 1964, 71, 247-256.

$\mathrm{KIMMEL}, H$. D. Instrumental conditioning of autonomically mediated behavior, Psychol Bull., 1967, 67, 337-345.

KIMIMIL, H. D., \& BAXTER, R. Avoidance conditioning of the GSR. $J$. exp. Psychol, 1964, 68, 482-485.

LINDQUIST, F. F, Design and analysis of experiments in psychology and education. Boston: Houghton-Mifflin, 1953.

MOORE, J. W., \& GORMEZANO, I. Yoked comparisons of instrumental and classical eyelid conditioning. J. exp. Psychol, 1961, 62, 552-559. NOTES

1. Even in studies using skcletal responses such as the eyelid reflex there is no assurance that the performance level achieved by avoidance Ss will be so high as to preclude conditioning of yoked controls (Moore \& Gormezano, 1961 ).

2. This study is the second author's Ph. D. dissertation research.

\section{Free association, free recall, and stimulated recall compared'}

EDWARD A. BILODEAU, TULANE UNIVERSITY, NeW Orleans, Louisiana, AND PAUL W. FOX, UNIVERSITY OF MINNESOTA, Minneapolis, Minnesota

Three primary methods of recall (free association, free recall, stimulated recall) and two modifications of them (modified free association, modified stimulated recall) were defined by use of three variables: (a) presence or absence of prior laboratory training, (b) presence or absence of $E$ controlled test stimulation, and (c) test instructions to free associate or to recall. Data obtained from approximately 300 Ss and an earlier set of 600 revealed the differential effectiveness of all three primary methods in recall and misrecall.

Behaviors of free association and retention share considerable variance (Bilodeau, 1966: Bilodeau \& Howell, in press). Until recently it was commonplace for word association and wordrecall behavior to be treated as if they were only weakly related: no study has yet been performed which provides a systematic evaluation of the communalities and differences among what appear to be three major ways of looking at the problem of word retrieval in recall. This experiment will provide such an evaluation.
FREE ASSOCIATION, FREE RECALL

AND STIMULATED RECALL COMPARED

The standard method of free association presents a test stimulus to which there has been no prior formal training in responding. In free recall, a test is introduced only after the deliberate manipulation of formal laboratory training, but the test itself deliberately omits the use of a stimulus. This differential stress upon the training or test environment should not be allowed to blur the idea that both methods tap memorial processes. In the case of free association, it is memory for materials acquired over the span of time prior to $S$ 's appearance at the laboratory. In the free-recall experiment, $S$ may respond as a function of pre-experimentally or experimentally acquired word-association habits and whichever component is the stronger depends upon $E$. In the case of free recall, $E$ can achieve a purchase upon such behaviors by the selection of training materials which are pre-experimentally associatively related (e.g., Deese, $1959 \mathrm{a}, \mathrm{b}$ ). Where $\mathrm{E}$ deliberately varies the stimuli within the recall environment, proacting pre-experimental associative processes can exest even more powerful influences upon S's recall or misrecall than training variations. This phenomenon was demonstrated by Bilodeau, Fox, \& Blick (1963), who combined features of the methods of free association and free recall, thereby creating the method of stimulated recall. The combination was effected by training $S$ on word material drawn from a pool of $100 R_{2}$ items tabled in the 1954 association norms of Russell and Jenkins (an $R_{2}$ is the second most frequently occurring associate in the hierarchy of free-association responses), and testing for recall of $\mathbf{R}_{\mathbf{2}}$ in the presence of the stimulus term. The essential features of stimulated recall are: (a) a standard laboratory training session, (b) a test instruction to recall, and (c) introduction of stimuli into the test period which are preexperimentally rather than experimentally related to the words of training.

The independent variables defining free association (FA), stimulated recall (SR), and free recall (FR) are outlined in Table 1 along with two important variants. Rows represent the independent variables and columns identify the retention methods. The manipulated variables include (a) prior experimental training or not, (b) type of recall instructions and, (c) presence or absence of stimuli during recall. When stimuli are present in recall, they can be explicitly brought to S's attention (as in standard SR), or as in the case of modified SR (MSR), the recall instructions may make no mention of such stimuli and their employment.

For modified FA (MFA), the operational accent is on the presence of a training period prior to testing. Bilodeau et al

Table 1

Summary of Operations Defining Five Methods of Recall

\begin{tabular}{lllllll} 
& \multicolumn{3}{c}{ Primary Methods } & & \multicolumn{2}{c}{ Modified Methods } \\
\cline { 2 - 4 } Variable & FA & SR & FR & & MFA & MSR \\
\hline Prior Training & No & Yes & Yes & & Yes & Yes \\
Instruction to Recall & No & Yes & Yes & & No $^{1}$ & Yes \\
Test Stimulns & Yes & Yes & No & & Yes & Yes $^{2}$ \\
\hline
\end{tabular}

${ }^{1} N o$ is actually an instruction to free associate. The stressing operations are italicized.

${ }^{2}$ The stimulus, though present, is not called to S's attention. 
(1963), have asked if their patterns of recall and misrecall in SR represented more than mere free associations following a laboratory training experience. It may be said that such a training experience primes recalls of $R_{2}$ in SR (Cofer, 1967), thus changing the response pattern independently of actual interference and/or facilitation produced by the stimulus. MFA will enable the testing of the assertion that $S R$ is not a construction process but only a variation of FA; other hypotheses are embedded in Table 1.

The triangles in Fig. 1 display word-retrieval probabilities for $R_{2}, R_{1}$, or $R_{3-n}$ obtained under $F A, S R$, and $F R$ in earlier research. The $S R$ and $F R$ values of Fig. 1 are adapted from the data of Bilodeau et al (1963), in which $R_{2} s$ represent correct recalls and $R_{1} s$ and $R_{3-n} s$ are misrecalls or extra-experimental intrusions. The FA data are taken from the Russell \& Jenkins (1954) norms for the same hierarchies and words. Figure 1 clears up several points. Most important is that FA, FR, and SR yield widely different levels of recall. The two modified methods have been arranged on the triangle in terms of their estimated involvement in recall processes because no data are available to post.

Although the primary methods are placed at the corners of a triangle, they are presently conceived as delimiting areas of operation, not simple points. The triangular representation is only a first approximation to the complex interrelationships among retention methods that are at issue here.

\section{Subjects}

\section{METHOD}

Basic airmen trainees at Keesler AFB were used. Of $\mathbf{3 0 5}$ Ss, 10 were voided for failure to follow directions and five others were dropped so as to achieve equal $\mathrm{Ns}$, or $\mathbf{5 8}$ for each of five groups.

\section{Procedure}

The five methods are described in Table 2 where the major events of training and testing are outlined. The words studied on Pages $A$ and $B$ were all $R_{2}$ s. Training consisted of two lists to study (except for FA), only one of which $S$ was asked to recall.

(1) Free Association (FA). The first three pages of the booklet (events A through C) called for vowel cancelling for Group FA. This busied $S$ during the times when the other groups were being trained. Page D presented the FA task itself and displayed five printed stimulus words and typical FA instructions: "This page contains five words. Look at a word and write the first word it makes you think of. You must fill in every line. Do not look back to the previous pages."

(2) Modified Free Association (MFA). With the exception of events $A$ and $B, M F A$ was like $F A$. Five $R_{2}$ words were exposed on pages $A$ and $B$, each list for $20 \mathrm{sec}$, and $S$ was instructed to "Study the words shown below." Free association on Page D was to the five stimuli which normally evoke the $R_{2} s$ of Page $B$ in earlier norms. MFA combines the typical training experience of a recall experiment with $F A$ instructions.

(3) Free Recall (FR). Training was identical to MFA. Page D contained five blanks for recall, no word stimuli, and the following instructions: "A while ago you studied some words on two pages, A and B. Write down the words that appeared on the second page, Page B. You must fill in every line. If you cannot remember, write in the first word that you think of. Do not look back to the previous pages."

(4) Stimulated Recall (SR). Training on events A and B was the same as for MFA and FR. Event D differed in that the Ss were instructed to recall the words of Page $B$ in the presence of the five stimuli. In addition, the instructions to recall brought the printed stimuli to S's attention as follows: "A while ago you studied some words on two pages, A and B. The words below may help you to remember those words. Write down the words that appeared on the second page, Page B. You must fill in every line. If you cannot remember, write in the first word that the printed word makes you think of. Do not look back to the previous pages."

(5) Modified Stimulated Recall (MSR). The training and VC pages were identical to those of MFA, FR, and SR. The form of the recall page was the same as SR except for one matter: the instructions were identical to those of FR. Thus, the stimuli were present in recall but no mention was made of them.

Table 2

Experimental Design and Sequence of Events

\begin{tabular}{|c|c|c|c|c|}
\hline Group Name & Event A & Event B & Event C & Event D \\
\hline 1. (FA) Free Assoc. & vc & vC & VC & $\begin{array}{l}\text { Free assoc. to } \\
5 \text { stim. words }\end{array}$ \\
\hline $\begin{array}{l}\text { 2. (MFA) Modified } \\
\text { Free Assoc. }\end{array}$ & $\begin{array}{c}\text { Study } 5 \\
\mathrm{R}_{2} \mathrm{~s}\end{array}$ & $\begin{array}{l}\text { Study } 5 \\
R_{2} s\end{array}$ & vC & $\begin{array}{l}\text { Free assoc. to } \\
5 \text { stim. words }\end{array}$ \\
\hline 3. (FR) Free Recall & $\begin{array}{l}\text { Study } 5 \\
\mathbf{R}_{2} \mathrm{~s}\end{array}$ & $\begin{array}{l}\text { Study } 5 \\
\mathrm{R}_{2} \mathrm{~s}\end{array}$ & vC & $\begin{array}{l}\text { Free recall of } \\
\text { Page B }\end{array}$ \\
\hline 4. (SR) Stim. Recall & $\begin{array}{c}\text { Study } 5 \\
\mathbf{R}_{2} \mathbf{s}\end{array}$ & $\begin{array}{l}\text { Study } 5 \\
R_{2} s\end{array}$ & vC & $\begin{array}{l}\text { Stim. Recall of } \\
\text { Page B with stand- } \\
\text { dard instructions }\end{array}$ \\
\hline $\begin{array}{l}\text { 5. (MSR) Modified } \\
\text { Stim. Recall }\end{array}$ & $\begin{array}{c}\text { Study } 5 \\
\mathbf{R}_{2} \mathbf{s}\end{array}$ & $\begin{array}{l}\text { Study } 5 \\
R_{2} S\end{array}$ & vc & $\begin{array}{l}\text { Stim. present for } \\
\text { recall of B, but } \\
\text { not mentioned, i.e., } \\
\text { FR instructions }\end{array}$ \\
\hline Time in sec & 20 & 20 & 120 & 120 \\
\hline
\end{tabular}



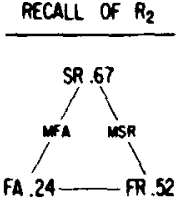

MISRECALL OF $R_{1}$ OR $R_{3-n}$
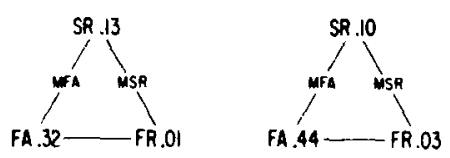

Fig. 1. Recall probabilities for three positions in the associa. tive hierarchy for FA, SR, and FR.

\section{Materials.}

Five $R_{2} s$ and their stimuli were selected from the Discrete norms of Bilodeau \& Howell (1965) to provide the items of Pages $B$ and D. Selection of items was based upon two associative criteria. First, both $R_{1}$ and $R_{2}$ ought to be stable or reliably evoked. Another norm (continued association at $C_{1}$ or $S$ 's first opportunity to associate to the stimulus) served as the check on reliability. This rule maximized the chances for stable hierarchies and provides a reliable base of FA data against which to evaluate changes in the hierarchy anticipated under the other methods. Second, inter-item associations among the words of Page B and among the test stimuli ought to be made low; a mean probability of $p=.00$ being achieved. "Bath," "short," "mutton," "stem," and "man" were the stimuli of page D; the corresponding Page B words or $\mathrm{R}_{2} \mathrm{~s}$ were: "water," "long," "sheep," "plant," and "boy." In the Discrete norms, mean $p\left(R_{1}\right)=.46, p\left(R_{2}\right)=.15$, and $\mathrm{p}\left(\mathrm{R}_{3-\mathrm{n}}\right)=.39$.

Ten word orders per page were generated by the use of two 5 by 5 Latin squares and a different word order for every six Ss within methods. Stimulus placement on the test page always conformed to the word order on Page B. Ten additional words were chosen for filler material on Page A of training, five being used with half of the Ss in each method and the other five used for an equal number of $S s$ within methods. The experiment was carried out in 3 sessions of approximately 100 Ss with E assisted by 2 proctors.

The $1450(5 \times 5 \times 58)$ responses were assigned to one of seven categories: position in the associative hierarchy $\left(R_{1}, R_{2}, R_{3-n}\right)$; same-list response (a Page $B$ word written on a different line in the test from that appearing in training); other-list intrusion (an intrusion from Page A); Blank (a failure to respond); and Remainder (none of the previous six).

\section{RESULTS}

\section{Correct recall $p\left(\mathbf{R}_{2}\right)$}

The triangle on the left of Fig. 2 gives $p\left(R_{2}\right)$. The right-hand triangle also presents $R_{2}$ but includes same-list responses. As expected, only under FR, where Ss are tested for recall without stimuli, does the difference in scoring matter.
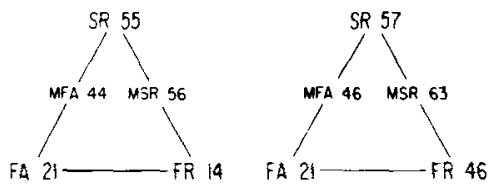

$$
D\left(R_{2}\right)
$$$$
\text { D }\left(R_{2}\right)+\text { Same }
$$

Fig. 2. $\mathbf{R}_{2}$ probabilities scored by two procedures for the five methods.
Figure 2 clearly reveals the different behaviors obtained under the five methods. For $F A, p\left(R_{2}\right)=.21$. Training $S$ by a brief exposure to $R_{2}$ as in MFA has the effect of doubling $R_{2}$ (i.e., .44). Identical training conditions, but under instructions to recall in the presence of the stimuli (i.e., methods SR and MSR), leads to a further increase in $p\left(R_{2}\right)$, with over $20 \%$ more $R_{2} s$ given by SR and MSR than under MFA. This increase for SR argues strongly against the hypothesis that $\mathrm{Ss}$ merely free associate following preexposure to items during training. ${ }^{2}$

The performance of MSR is noteworthy for its comparability to SR. In effect, MSR tests the generality and robustness of the SR procedure since it shows whether stimulus specification and instructions encouraging association are necessary to produce data typical of SR. As Fig. 2 shows, the simple presence of the stimuli on the recall page, in itself, was indeed sufficient to evoke comparable retrieval. The frequency distribution in Table 3 emphasizes this finding by showing the number of Ss by group giving $0-1,2-3$, or $45 R_{2} s$ in recall. The distributions shift from positively skewed for FA to negatively skewed for SR and MSR, with MFA and FR displaying fairly flat profiles. In terms of the number of Ss, SR and MSR produce extremely similar distributions; no deviation between the two distributions exceeds three Ss for any class of $R_{2}$, while the form of the distributions for $S R$ and MSR differs markedly from those of FR, MFA, and FA:

Table 3

Number of Ss Giving $R_{2} s$ for Each Method of Recall

Method of Recall

\begin{tabular}{cccccc}
\cline { 2 - 6 } No. of $R_{2}$ s & FA & MFA & FR & MSR & SR \\
\hline $0-1$ & 40 & 23 & 19 & 9 & 10 \\
$2-3$ & 17 & 21 & 24 & 25 & 27 \\
$4-5$ & 1 & 14 & 15 & 24 & 21 \\
\hline
\end{tabular}

\section{Errors of memory and non- $R_{2}$ Associates}

Table 4 displays five ways of examining misrecall. FA produces $.33 \mathrm{R}_{1} \mathrm{~s}$, a few more than does MFA. A comparison of Fig. 2 with Table 4 shows that the relative strengths of the $R_{1}$ and $R_{2}$ terms have in fact been inverted by the MFA procedure. Further, SR gives (a) even fewer $R_{1} s$ than MFA, and (b) proportionately fewer than MFA compared to FA. Finally, FR produces no $R_{1}$ errors. The results from $R_{3-n}$ are highly correlated with $R_{1}$ and they support one another. For Other, Remainder, and Blank, SR and MSR show few while FR shows many.

\section{DISCUSSION}

In $F A, S$ produced the designated item $\left(\mathrm{R}_{2}\right)$ as estimated from pre-experimental normative response strength. The response pattern took the ordinary hierarchial form of $R_{1}, R_{2}$, and $R_{3-n}$ and most but not all responses were located by reference to cultural norms. In the present case. the Bilodeau and Howell norms identified $81 \%$ of responses given by FA. By exposing the target words prior to free association, E modified the hierarchy characterizing FA. We expected the training to increase the occurrence of the target items and lower the incidence of non-target items during recall and it did. This is the phenomenon of direct associative priming (Cofer, 1967) and it occurred here with considerable magnitude. While the level of $R_{2}$ was greatly increased over standard FA levels, $R_{1} s$ did not diminish by an 
Table 4

Five Classifications of Misrecall Probabilities Obtained under the Five Methods

\begin{tabular}{lccccc} 
& \multicolumn{5}{c}{ Response Probability } \\
\cline { 2 - 6 } Method & $\mathbf{R}_{1}$ & $\mathbf{R}_{\mathbf{3}-\mathbf{n}}$ & Other & Remainder & Blank \\
\hline FA & .33 & .27 & .00 & .18 & .01 \\
MFA & .22 & .20 & .02 & .10 & .00 \\
SR & .13 & .15 & .03 & .07 & .04 \\
MSR & .10 & .06 & .04 & .11 & .05 \\
FR & .00 & .01 & .19 & .22 & .12 \\
\hline
\end{tabular}

equal amount. Instead, prior training on $\mathbf{R}_{2}$ (as in MFA) served to concentrate the majority of responses in the $R_{2}$ and $R_{1}$ classes and to reduce the remainders somewhat.

There is little reason to expect that word association processes would play much of a role in FR because no stimuli for association were offered and inter-item associations among the words if training were reduced to zero. Thus, FR represented a minimum opportunity for overt, E manipulated association during recall, and the FR data bore this out when virtually all of FR responses fell outside the associative hierarchy.

The instruction to recall in the presence of test stimuli systematically altered recall compared to FA and MFA. First, SR produced over $20 \%$ more $R_{2} s$ than expected on the basis of free association following training (MFA), and nearly tripled the rate of $R_{2} s$ produced under $F A$. Second, extra-experimental intrusions of $R_{1} s$ and $R_{3-n} s$ accounted for more than one fourth of the responses by $\mathrm{SR}$. This was only moderate when compared to responses in these classes by MFA and FA, but is large relative to the level of such intrusions in the typical recall task (Blick, 1965). When compared, FA, MFA, and SR lead to almost the same number of responses located in the Bilodeau and Howell norms $(81,86$, and $86 \%$ of all responses, respectively), but it is their distribution which differs. The thesis that SR produces mere word association behaviors following training (i.e., MFA) is refuted in the present data as it was earlier (Fox, in press).

The retrieval patterns characterizing SR hold up very well as a descriptive base for MSR as well. Explicit specification of the test stimulus in SR does not appear to be a critical variable producing the distinctive pattern. Instead, the presence qua presence of the test stimulus during recall, specified or not, appears the major variable distinguishing $S R$ from $F R$ procedures.

Two conclusions emerge from the patterns of word retrieval resulting from the mixing of the variables of Table 1. First, an account of what words will be produced during the test period should not be restricted to occurrences of the target items, and must include misrecalls. Second, the three primary methods do in fact represent three diverse though related points of departure for the study of recall.

\section{REFERENCES}

BILODEAU, E. A. Retention. In E. A. Bilodeau (Ed.), Acquisition of skill. New York: Academic Press, 1966. Pp. 315-350.

BILODEAU, E. A., \& BLICK, K. A. Courses of misrecall over long-term retention intervals as related to strength of pre-experimental habits of word association. Psychol Rep., 1965, 16, 1173-1192, Monogr. Suppl. 6-V16.

BILODEAU, E. A., FOX, P. W., \& BLICK, K. A. Stimulated verbal recall and analysis of sources of recall. J. verbal Leam. verbal Behav., 1963, 2, $422-428$.

BILODEAU, E. A., \& HOWELL, D. C. Free association norms. U. S. Gov't Print. Office, Washington, D. C., 1965. Cat. No. D210.2:F87.

BILODEAU, E. A., \& HOWELL, D. C. Association rules in the prediction of recall from free-association matrices. Psychol. Bull., in press.

BLICK, K. A. Cultural primaries as a source of interference in short-term verbal retention. J. exp. Psychol, 1965, 69, 246-250.

COFER, C. N. Conditions for the use of verbal associations. Psychol. Bull. $1967,68,1-12$.

DEESE, J. On the prediction of occurrence of particular verbal intrusions in immediate recall. J. exp. Psychol., 1959a, 58, 17-22.

DEESE, J. Influence of inter-item associative strength upon immediate free recall. Psychol, Rep., 1959b, 5, 305-312.

FOX, P. W. Recall and misrecall as a function of cultural and individual word association habits and regulation of the recall environment. $J$. verbal Learn. verbal Behav., in press.

RUSSELL, W. A., \& JENKINS, J. J. The complete Minnesota norms for responses to 100 words from the Kent-Rosanoff Word Association Test. Tech. Rep. No. 11, 1954, Contract No. N8ONR-66216, Office of Naval Research and University of Minnesota.

$$
\text { NOTES }
$$

1. Mainly supported by Contract Nonr-475 (10) between Tulane University and the Office of Naval Research. The second author was supported by grants to the University of Minnesota Center for Rescarch in Human Learning from NSF. (GS1761), NICHHD, (PO1-HD-01136), and the Graduate School of the University. The authors wish to thank Cecil Rogers, Jr., David C. Howell, and Christopher Spatz for their generous assistance.

2. The reliability of the data of Fig. 2 was checked by reference to a prior experiment. The earlier study was identical in all respects except for using only two $n$ ord orders per page rather than 10 . Based on over $600 \mathrm{Ss}$, approximately 120 per method, $p\left(R_{2} s\right)$ were as follows: $F A=.20, \mathrm{MFA}=$ $.44, \mathrm{SR}=.57 . \mathrm{MSR}=.51$, and $\Gamma \mathrm{R}=.45$. The reader should note that. except in the case of MSR, none of these ps deviate by more than 01 or .02 from the value in Fig. 2. This validation is offered as a substitute for $\mathrm{F}$ tests with the data generated by the 300 Ss. 